\title{
A IMPLEMENTAÇÃO DE POLÍTICAS PÚBLICAS PARA O GERENCIAMENTO DE ÁREAS DE RISCOS: AÇÃO DA DEFESA CIVIL DO DISTRITO FEDERAL (DF)
}

\author{
Pedro Paulo Mesquita Mendes ${ }^{1}$
}

\author{
Paulo Henrique Kingma Orlando ${ }^{2}$
}

\begin{abstract}
RESUMO
O presente artigo procura trazer algumas reflexões sobre a temática em torno das Politicas Públicas, e as principais áreas de risco que estão concentradas em quatro localidades no Distrito Federal: Fercal, Sol Nascente (Ceilândia), Vila Rabelo e Vicente Pires, devido à ocupação irregular, sem a necessária infraestrutura. Este tema vem ocupando cada vez mais a agenda política do governo brasiliense, frente aos constantes acidentes que vem vitimando parcela significativa da população que reside em áreas impróprias para a ocupação. Destacamos principalmente alguns marcos regulatórios e diretrizes gerais sobre política urbana contidas na constituição Federal de 1988; a Lei № 10.257, de 10 de julho de 2001 o Estatuto da Cidade; a criação do Ministério das Cidades (2003) assim como as diretrizes do Sistema Nacional de Defesa Civil (SINDEC).
\end{abstract}

Palavras-chave: Políticas Públicas; Áreas de Risco; Espaço Urbano.

\section{IMPLEMENTATION OF PUBLIC POLICIES FOR RISK MANAGEMENT AREAS: ACTION CIVIL DEFENSE OF THE FEDERAL DISTRICT (DF)}

\footnotetext{
ABSTRACT

This article tries to give some reflections on the theme around Public Policy, and the main areas of risk that are concentrated in four locations in the Federal District: Fercal, Rising Sun (Ceilândia), Vila Rabelo and Vicente Pires, due to the illegal occupation without the necessary infrastructure. This topic

${ }^{1}$ Estudante do programa de Pós-graduação da Universidade Federal de Goiás/Regional Catalão pedropaulo.mendes@hotamail.com

2 Professor Adjunto II da Universidade Federal de Goiás/Regional Catalão e Professor do Programa de Pós-Graduação em Geografia-Regional de Catação/UFG - phorlando@yahoo.com.br
} 


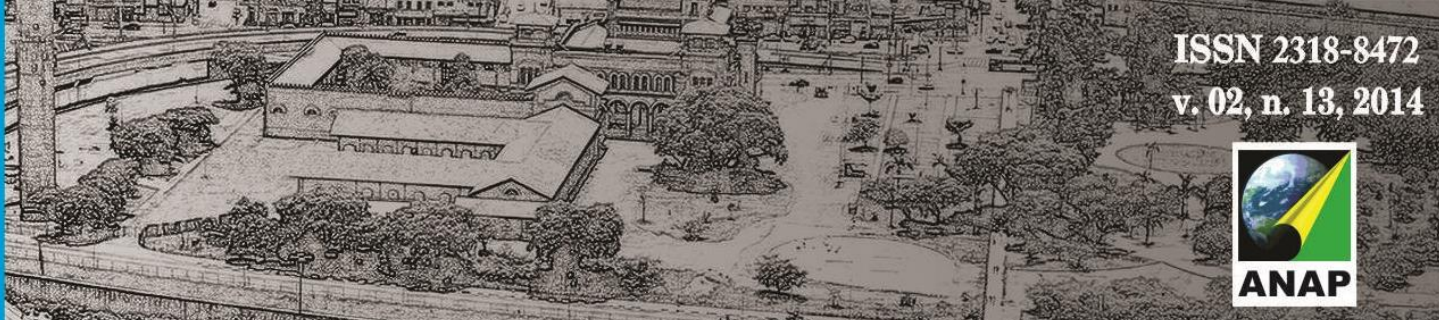

Revista Nacional de

Gerenciamento de Cidades

has been occupying increasingly political agenda brasiliense government, compared to constant accidents that comes victimizing significant portion of the population living in areas unsuitable for occupation. Mainly highlight some regulatory frameworks and guidelines on urban policy contained in the Federal Constitution of 1988; Law No. 10.257, of July 10, 2001 the City Statute; the creation of the Ministry of Cities (2003) as well as the guidelines of the National System of Civil Defense (SINDEC).).

Keywords: Public Policy, Risk Areas, Urban Space.

\section{APLICACIÓN DE LAS POLÍTICAS PÚBLICAS PARA ÁREAS DE GESTIÓN DE RIESGOS: ACCIÓN DEFENSA CIVIL DEL DISTRITO FEDERAL (DF)}

\section{RESUMEN}

Este trabajo intenta dar algunas reflexiones sobre el tema en torno a las políticas públicas, y las áreas clave de riesgo que se concentran en cuatro lugares en el Distrito Federal: Fercal, Rising Sun (Ceilândia), Rabelo Village y Vicente Pires, debido a la ocupación irregular sin la infraestructura necesaria. Este tema ha estado ocupando cada vez más la agenda política del gobierno de Brasilia, frente a los accidentes constantes que viene victimizando porción significativa de la población que vive en zonas no aptas para la ocupación. Principalmente destacar algunos marcos normativos y directrices sobre política urbana contenidas en la Constitución Federal de 1988; la Ley N • 10.257, de 10 de julio de 2001, el Estatuto de la Ciudad; la creación del Ministerio de las Ciudades (2003), así como los lineamientos del Sistema Nacional de Defensa Civil (SINDEC).

Palabras-clave: Políticas Públicas; Áreas de riesgo; Espacio Urbano.

\section{INTRODUÇÃO}

O conceito de Políticas Públicas é amplo e de difícil definição por existir uma grande extensão na discursão no campo teórico. Com isso, definir o conceito de Políticas Públicas é uma tarefa árdua por causa da relação com os aspectos sociais, históricos, econômicos, levando uma gama de possibilidades analíticas. Contudo, devemos observar as Políticas Públicas além das medidas legislativas.

Seguindo a concepção que as políticas públicas é um auxiliador nas tomadas de decisões, com isso, sua implementação não pode ser um entrave para o desenvolvimento econômico, sendo assim, um promovedor de ganhos para esfera 


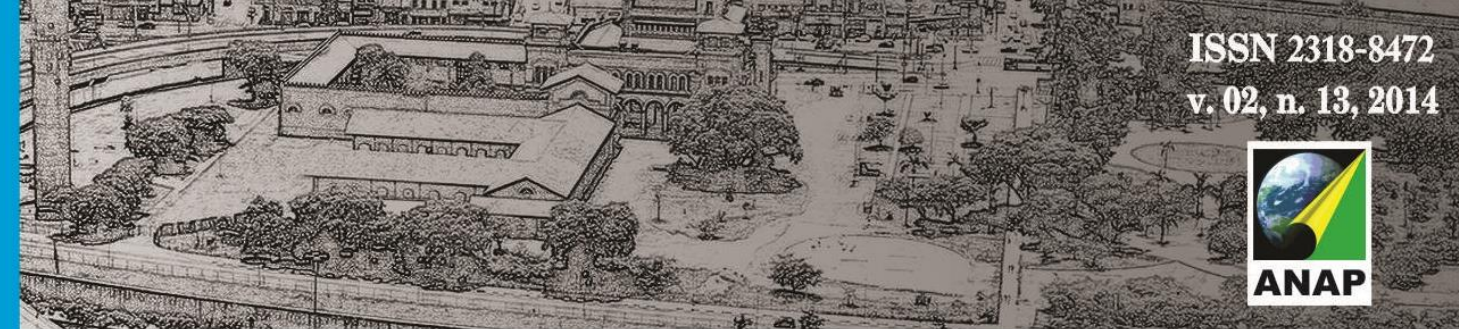

Revista Nacional de

Gerenciamento de Cidades

produtiva. As ações das políticas públicas devem compensar os desajustes sociais, ampliar e efetivar os direitos garantidos constitucionalmente, respaldar os setores vulneráveis e minimizar os conflitos de interesses de grupos.

As políticas públicas para áreas de risco do Distrito Federal são gerenciadas pela Secretaria de Estado da Defesa Civil do Distrito Federal. A Defesa Civil é um conjunto de ações preventivas, de socorro, assistenciais e recuperativas destinadas a evitar desastres e minimizar seus impactos para a população e restabelecer a normalidade social.

Por fim, podemos entender que política pública pode se definida como diretrizes e princípios de ações e programas, implementado pelo Estado, podendo ter a participação da esfera privada ou a sociedade organizada, tendo por objetivo garanti o mínimo de direito aos cidadãos. As ações e programas podem beneficiar os ramos educacionais, sociais, ambientais, culturais, econômicos e entre outros. As políticas públicas estão interligadas ao direito garantido constitucionalmente ou pelas necessidades de melhorias e manutenção da sociedade como um todo, desde o público ao privado.

Desta forma o presente artigo procura trazer algumas considerações sobre o conceito e definição de Políticas Públicas bem como aquelas criadas no âmbito da esfera federal que tem por objetivo principal equacionar o dramático cenário da população que reside em áreas sujeita a desabamento, enxurrada, inundação, contaminação, erosão e incêndio, as denominadas áreas de risco dentro do Distrito Federal.

\section{CONCEITOS BÁSICOS DE POLÍTICAS PÚBLICAS}

As políticas públicas podem ser definidas segundo Seccchi (2010) por duas abordagens. Sendo a abordagem estatista e a abordagem multicêntrica. $\mathrm{Na}$ concepção de Theodoulou (1995, p. 2) a política pública tem uma abordagem estatista quando 


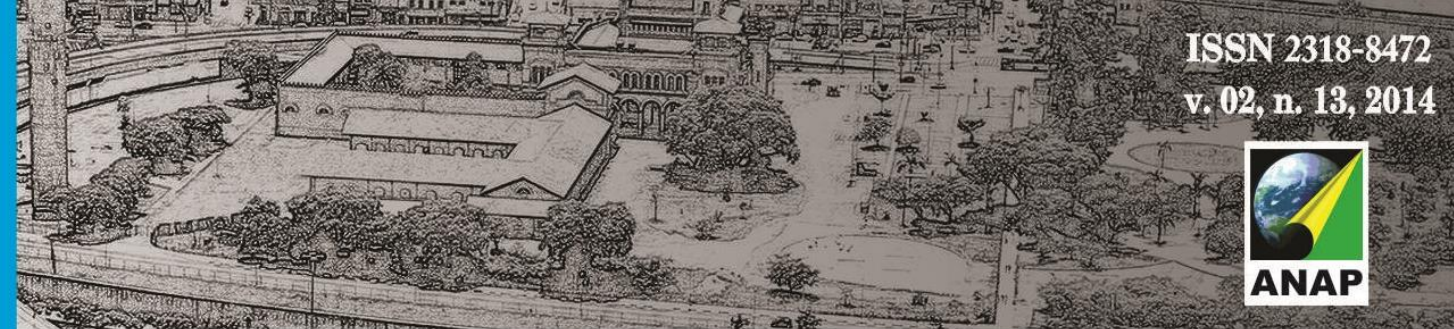

Revista Nacional de

Gerenciamento de Cidades

[...] a primeira ideia que alguém se depara é que a política pública deve distinguir entre o que os governos pretendem fazer e o que, na verdade eles realmente fazem; que a inatividade governamental é tão importante quanto a atividade governamental. O segundo elemento é a noção de que política pública envolve idealmente todos os níveis de governo e não é necessariamente restrito aos atores formais, informais atores também são extremamente importantes. (THEODOULOU, 1995, p. 2)

Seguindo a abordagem estatista segundo Appio (2005) as políticas públicas podem ser entendidas como "instrumentos de execução de programas políticos baseados na intervenção estatal na sociedade com a finalidade de assegurar igualdade de oportunidade aos cidadãos, tendo por escopo assegurar as condições materiais de uma existência digna a todos".

Dentro da abordagem multicêntrica, de acordo com Heidemann (2010), aponta que "A perspectiva de política pública vai além da perspectiva de políticas governamentais, na medida em que o governo, com sua estrutura administrativa, não é a única instituição a servir à comunidade política, isto é, a promover políticas públicas".

Dentro da concepção multicêntrica a participação da sociedade para formulação das políticas públicas tem um papel importante na tomada de decisão. A participação da sociedade é garantida por lei. Segundo a Lei Complementa n. 131 (Lei da Transparência), de 27 de maio de 2009, quanto à participação da sociedade, assim determina:

I - incentivo à participação popular e realização de audiências públicas, durante os processos de elaboração e discussão dos planos, lei de diretrizes orçamentárias e orçamentos;"

II - liberação ao pleno conhecimento e acompanhamento da sociedade, em tempo real, de informações pormenorizadas sobre a execução orçamentária e financeira, em meios eletrônicos de acesso público; (BRASIL, 2009)

Entretanto, outros autores definem políticas públicas sem estarem ligadas a abordagem estatista ou multicêntricas.

Segundo Guareschi (2004, p. 24) em seu artigo "Problematizando as práticas psicológicas no modo de entender a violência" entende-se por Políticas Públicas sendo 


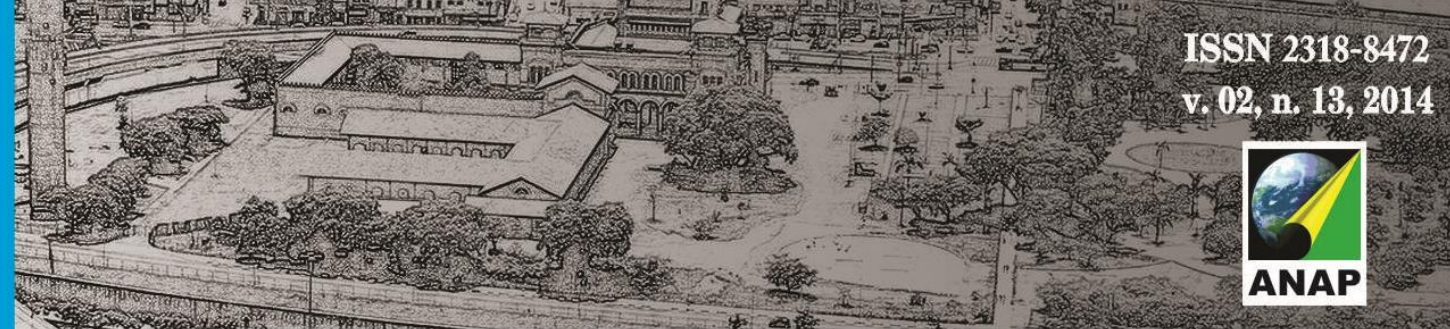

Revista Nacional de

Gerenciamento de Cidades

[...] o conjunto de ações coletivas voltadas para a garantia dos direitos sociais, configurando um compromisso público que visa dar conta de determinada demanda, em diversas áreas. Expressa a transformação daquilo que é do âmbito privado em ações coletivas no espaço público. GUARESCHI (2004, p. 24)

Já Souza apud Oliveira (2006, p. 24) em seu artigo titulado "Políticas Públicas: uma revisão da literatura" aponta que há varias definições para políticas públicas. Mead (1995) a define como um campo dentro do estudo da política que analisa o governo à luz de grandes questões públicas e segundo Lynn (1980), como um conjunto de ações do governo que irão produzir efeitos específicos. Peters (1986) segue o mesmo veio Lynn: política pública é a soma das atividades dos governos, que agem diretamente ou através de delegação, e que influenciam a vida dos cidadãos. Dye (1984) sintetiza a definição de política pública como "o que o governo escolhe fazer ou não fazer".

As políticas públicas é o instrumento formulador para a orientação de tomada de decisões para o bem estar público. Contudo Rua (2009, p.20) afirma que "embora uma política pública implique decisão política, nem toda decisão política chega a construir uma política pública".

Souza (2006) ao elaborar uma revisão conceitual das Políticas Públicas destaca que esta vem adquirindo importância significativa tendo em vista alguns fatores que contribuíram para a visibilidade dessa temática, entre eles destaca a adoção de políticas restritivas de gastos por parte dos governos, principalmente dos países em desenvolvimento como o Brasil, devido as mudanças decorrentes da substituição de políticas Keynesianas por políticas restritivas a intervenção do Estado na economia e nas políticas sociais.

As Políticas Públicas são entendidas segundo a autora "como o campo do conhecimento que busca, ao mesmo tempo, "colocar o governo em ação" e/ou analisar essa ação (variável independente) e, quando necessário, propor mudanças no rumo ou curso dessas ações (variável dependente). A formulação de políticas públicas constitui-se no estágio em que os governos democráticos traduzem seus 


\section{Revista Nacional de}

propósitos e plataformas eleitorais em programas e ações que produzirão resultados ou mudanças no mundo real (Souza, 2006, p.26).

Souza (2006, p. 36) sintetizando as diferentes definições sobre políticas públicas destaca os seguintes elementos que as perpassam: A Política Pública possibilita "distinguir entre o que o governo pretende fazer e o que, de fato, faz" envolvendo distintos "atores e níveis de decisão" tais como participantes formais e informais. Portanto constitui-se como uma ação intencional tendo em vista os objetivos a serem atingidos; assim, as políticas públicas posteriormente a sua formulação e definição são expressas mediante planos, projetos, base de dados e programas, sendo postas em ação e submetidas a avaliação e acompanhamento.

\section{A CRIAÇÃO DO MINISTÉRIO DAS CIDADES E AS POLÍTICAS PÚBLICAS}

De acordo com Maricato (2006, p. 214) "a proposta do Ministério das Cidades veio ocupar um vazio institucional que retirava completamente o governo federal da discussão sobre a política urbana e o destino das cidades".

A última proposta de política urbana implementada pelo governo federal, anterior a criação do Ministério das cidades, se deu no regime militar (1964-1985).

A criação do Ministério das Cidades representa a possibilidade de mudança no cenário urbano brasileiro, pois este através da criação e implementação de políticas públicas voltadas para intervir no verdadeiro caos urbano de muitas de nossas cidades, principalmente no tocante as áreas de risco, pode representar um alternativa para evitar o caos urbano.

Alguns projetos e ações merecem destaque, pois de certa forma procuram mitigar as situações precária de habitação de muitas famílias, por meio do Programa de Urbanização, Regularização e Integração de Assentamentos Precários objetiva destinar recursos para o estados e municípios, para que estes executem ações necessárias para que se possa garantir segurança, condições sanitárias e habitabilidade para a população brasileira que reside em áreas inadequadas. 
Tal programa está associado com um conjunto de ações, uma delas é a Ação de Apoio à Prevenção e Erradicação de Riscos em Assentamentos Precários que procura garantir a segurança da população de baixa renda que reside em áreas de risco.

Estas Políticas Públicas são financiadas por transferências de recursos do Orçamento Geral da União, com o objetivo de executar ações de redução de riscos, tais como o treinamento e capacitação de equipes.

Pode-se citar outras ações que, implementadas pelo Ministério das Cidades que tem por objetivo garantir um ambiente urbano com qualidade de vida para seus moradores, principalmente a parcela da população de menor renda, dentre elas temos:

O Programa Drenagem Urbana Sustentável, que procura "promover a ges tão sustentável dadrenagem urbana com ações estruturais e não estruturais dirigida $s$ à prevenção, ao controle eà minimização dos impactos provocados por enchentes urbanas e ribeirinhas"

e o Programa Terra Urbanizada Para Todos, que tem por objetivo principal"apoiara i mplementação do Estatuto da Cidade, ampliação do acesso, porparte da população de menor renda, à terra urbanizada".

Segundo Oliveira outro instrumento de gestão de áreas de risco em ambientes urbanos;

[...] são os Planos Municipais de Redução de Risco (PMRR) estes planos devem deve apresentar critérios técnicos e gerenciais que permita aos gestores municipais, a criação e implementação de ações estruturais e nãoestruturais, adequadas aos prazos e recursos contidos no orçamento municipal, estadual e da União. (OLIVEIRA, 2012)

O objetivo maior de um PMRR, é o de erradicar, controlar e reduzir as situações de risco associadas da dinâmica superficial e que colocam em perigo a vida e os bens materiais das populações inseridas nestas áreas. Sendo um instrumento de gestão urbana de fundamental importância para o controle e mitigação dos riscos nas cidades brasileiras. 


\section{Revista Nacional de}

A iminência de um desastre provocado por processos da dinâmica superficial como, enchentes e inundações, escorregamentos, solapamentos de margens, ou fortes vendavais, no Brasil como em muitos outros países tem na Defesa Civil a instituição responsável por realizar ações de mitigação, socorro e reconstrução após um evento extremo que tenha provocado danos para a sociedade. De acordo com Calheiros (2007) a Defesa Civil caracteriza-se como um conjunto de ações preventivas, de socorro, assistenciais e de reconstrução destinadas a evitar ou minimizar os desastres, preservar o moral da população e restabelecer a normalidade social .

Com o Decreto № 5.376 de 17 de Fevereiro de 2005 e revogado pelo Decreto $\mathrm{n}^{\circ} \mathbf{7 . 2 5 7}$, de 4 de agosto de 2010 , que dispõe sobre o Sistema Nacional de Defesa Civil (SINDEC), que reúne órgãos específicos da administração pública, juntamente com as entidades privadas e a comunidade responsáveis pelas ações de defesa civil em todo o território nacional, o SINDEC está sob coordenação da Secretaria Nacional de Defesa Civil, vinculada ao Ministério da Integração Nacional.

Desta forma o SINDEC é composto por um conjunto de órgãos específicos, setoriais e de apoio, cujo objetivo é planejar e promover a defesa permanente contra desastres, naturais ou provocados pelo homem, e atuar em situações de emergência e em estado de calamidade pública. Integra, no território nacional, ações de órgãos e entidades públicas e privadas, em interação com a comunidade, visando prevenir ou minimizar danos, socorrer e assistir populações atingidas e recuperar áreas deterioradas por eventos adversos (Calheiros, 2007, p. 10).

O Sistema Nacional de Defesa Civil tem por finalidade, conforme Brasil (2010):

I - planejar e promover a defesa permanente contra desastres naturais, antropogênicos e mistos, de maior prevalência no País;

II - realizar estudos, avaliar e reduzir riscos de desastres;

III - atuar na iminência e em circunstâncias de desastres;

IV - prevenir ou minimizar danos, socorrer e assistir populações afetadas, e reabilitar e recuperar os cenários dos desastres; 


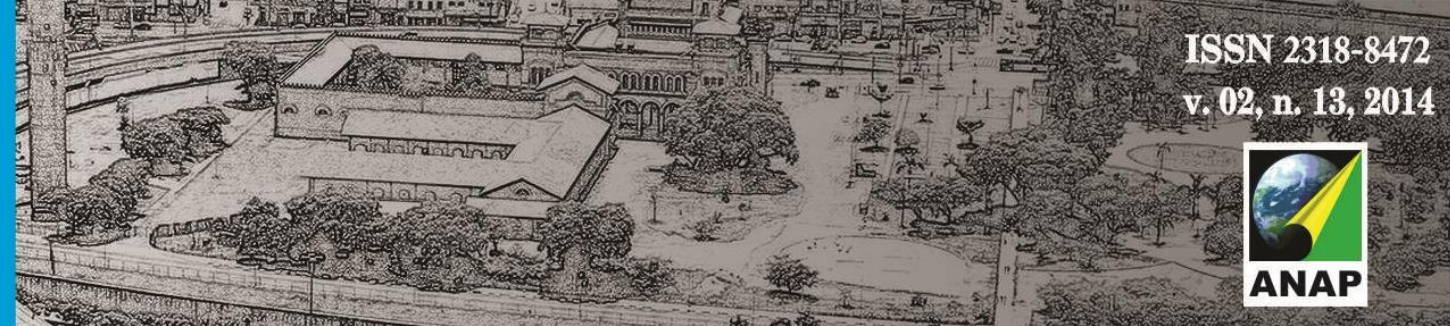

Revista Nacional de

Gerenciamento de Cidades

$\mathrm{V}$ - promover a articulação e coordenar os órgãos do SINDEC em todo o território nacional. (BRASIL, 2010)

Embora seja um órgão responsável pela elaboração de ações que vão desta a formulação de estratégias para a redução de desastres até as de reconstrução pós evento, o que se percebe no Brasil é que na maioria dos casos a Defesa Civil em muitos municípios atua principalmente no que se refere ao auxílio e reconstrução após o desastre.

É necessário que nos países em desenvolvimento aprimore-se mecanismos que interfiram sobre a vulnerabilidade dos elementos expostos ao risco através de instrumentos de gerenciamento, pois assim teremos subsídios técnicos como referência para a planejamento de um projeto de desenvolvimento que realmente posso melhorar a qualidade de vida em muitos assentamentos de nossas cidades.

\section{O GERENCIAMENTO DAS ÁREAS DE RISCO PELA SEDEC/DF}

O Sistema de Defesa Civil do Distrito Federa foi criado em 8 de junho de 1983, por intermédio do Decreto ํㅜ‥544, com a finalidade de coordenar as medidas destinadas a prevenir as conseqüências nocivas de eventos desastrosos e a socorrer as populações e áreas atingidas por esses eventos.

No dia 22 de dezembro de 1983, foi editado o Decreto ํㅜ 7.822, que organizou e regulamentou as atividades do Sistema de Defesa Civil do Distrito Federal, tendo por objetivo, promover a prevenção e a minimização de riscos e a preparação para os desastres no território do Distrito Federal; articular, mobilizar e coordenar meios para a redução dos desastres, a resposta e a reconstrução de cenários atingidos, envolvendo a comunidade nas ações de identificação de ameaças, vulnerabilidades e recursos, na busca de soluções para os problemas que afetam a vida, o patrimônio e o meio ambiente, visando a elevação do moral e a melhoria do bem-estar da população. 
Entretanto a Secretaria de Estado da Defesa Civil do Distrito Federal (SEDECDF) foi promulgada no dia 01 de janeiro de 2011, por meio do Decreto no 32.716. A SEDECDF é o Órgão da Administração Direta do Distrito Federal, tendo atuação e competência para defesa civil.

A SEDECDF prevê que seja implementado um modelo de Proteção Civil, onde se desenvolva na população a capacidade de percepção de risco e avaliação de ameaças, com o fim de reduzir a vulnerabilidade das pessoas e de abrir novos canais de comunicação entre sociedade e governo, visando minimizar riscos e consequentemente os desastres.

A SEDECDF utiliza a seguinte metodologia de avaliação para definir o grau de periculosidade das áreas de risco. Risco Muito Alto: desabamento, enxurrada, inundação, contaminação, erosão e incêncio. Risco Alto: assoreamento, erosão, enxurrada, alagamento e doenças. Risco Médio: contaminação do solo, contaminação do Lençol Freático e doenças.

No ultimo levantamento da SEDECDF no ano de 2013 foi constatado que existem 33 áreas consideradas de risco, em 15 Regiões Administrativas, por estarem localizadas em solo arenoso, argiloso ou próximos a encostas ou à beira de rios. Nesses locais existem cerca de 2.051 residências consideradas em situação de alto risco.

Além disso, nesse mesmo levantamento foi registrado a diminuição de quatro áreas de risco, em relação ao levantamento de 2012: Condomínio Privê, Bernardo Sayão, Parque Ecológico do Riacho Fundo I e Varjão

Esses locais de risco, não são áreas com construções planejadas, foram ocupados irregularmente em pontos propícios à erosão do solo e, portanto, sujeitos a deslizamentos e desabamentos.

As principais áreas de risco estão concentradas em quatro localidades: Fercal, Sol Nascente (Ceilândia), Vila Rabelo e Vicente Pires, devido à ocupação irregular, sem a necessária infraestrutura.

O órgão realiza também o constante monitoramento dos locais, averiguando a iminência do perigo e o crescimento dos riscos. Diante da 


\section{Revista Nacional de}

preocupação permanente com a vida das pessoas, a Defesa Civil fez 345 notificações e 88 interdições no ano de 2013.

Nessa atuação, eminentemente preventiva, a Defesa Civil tem contado com o envolvimento de lideranças comunitárias, administrações regionais, a parceria com a Casa Civil e outros envolvidos no planejamento e desenvolvimento urbano a fim de determinar a existência e o grau de vulnerabilidade e exposição a essas ameaças. A Defesa Civil lembra que é fundamental oportunizar conhecimento e capacitar as pessoas para minimizar os desastres, especialmente as que estão em áreas de riscos.

O órgão realiza também o constante monitoramento dos locais, averiguando a iminência do perigo e o crescimento dos riscos. Além disso, informa tanto os moradores quanto o governo sobre o que pode ser feito nas regiões.

Principais problemas encontrados no mapeamento realizado no ultimo levantamento: Ocupação irregular do solo; Falta de sistema de drenagem de águas pluviais; Falta de saneamento básico; Lixo e entulho; Esgoto a céu aberto; Estrutura precária das casas; Má fixação dos telhados das casas; Águas servidas são jogadas nas encostas; Casas próximas a erosão; Lixo e esgoto jogados em córregos; Difícil acesso dos bombeiros.

\section{CONSIDERAÇÕES FINAIS}

Podemos constatar que na última década, uma série de iniciativas foram implementadas por parte do poder público federal que estão contribuído para efetivar o que já estava previsto pela Constituição Federal de 1988 mas necessitava de regulamentos para que estas leis pudessem ser colocadas na prática e produzir políticas públicas eficientes para a gestão do ambiente urbano, ressaltando que estas estão sendo desenvolvidas com a participação da sociedade civil organizada.

A participação da sociedade deve ser contemplada em todas as etapas, desde a elaboração até a fase de acompanhamento dos projetos, pois somente assim teremos um processo realmente democrático de gestão urbana. 


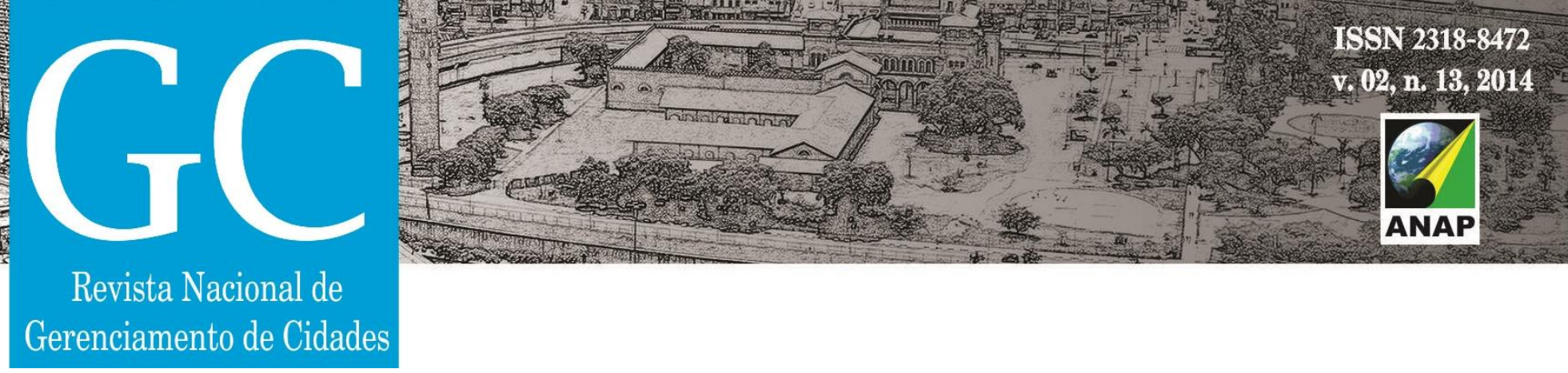

Desta forma é necessário que essas políticas se efetivem com um diálogo permanente entre os gestores públicos, instituições de pesquisa e a comunidade, e assim venham a contribuir para o gerenciamento efetivo das áreas de risco em nossas cidades, trazendo mais segurança para as comunidades afetadas pelos desastres naturais, que infelizmente ainda continuam a provocar mortes, prejuízo econômico e ambiental.

\section{REFERÊNCIAS}

BONETI, L. W. Políticas Públicas, Educação e Exclusão Social. In: Educação, Exclusão e Cidadania. ljuí: Ed. Unijuí, 2000.

BRASIL. DECRETO № 7.257, DE 4 DE AGOSTO DE 2010. Regulamenta a Medida Provisória no 494 de 2 de julho de 2010, para dispor sobre o Sistema Nacional de Defesa Civil-SINDEC, sobre o reconhecimento de situação de emergência e estado de calamidade pública, sobre as transferências de recursos para ações de socorro, assistência às vítimas, restabelecimento de serviços essenciais e reconstrução nas áreas atingidas por desastre, e dá outras providências. Publicado no Diário Oficial de 5 de agosto de 2010, Brasília, 2010. Disponível em: <http://www.planalto.gov.br/ccivil_03/_Ato2007-2010/2010/Decreto/D7257.htm>. Acesso em: 20/11/2013

CALHEIROS,L.B(org) Conferência geral sobre desastres: para prefeitos, dirigentes deinstituiçõe s públicas e privadas e líderes comunitários. Ministério da Integração Nacional, Secretaria Nacional de Defesa Civil. Brasília, 2007. Disponível em: <http://www.defesacivil.gov.br/publicacoes/publicacoes/conferencia.asp> Acesso em: 20/11/2013.

COELHO, M. C. N. Impactos ambientais em áreas urbanas - Teorias, conceitos e métodos de pesquisa. In: GUERRA, A. J. T.; SILVA, A. S.; BOTELHO, R. G. M. (Orgs.) Impactos ambientais urbanos no Brasil. Rio de Janeiro: Bertrand Brasil, 2011. p. 19-43

DUARTE, Fábio. Planejamento urbano. Curitiba: IBPEX, 2007. 177 p.

GUARESCHI, N. M. F. ;COMUNELLO, L. N. ; NARDINI, M. \& HOENISCH, J. C. . Problematizando as práticas psicológicas no modo de entender a violência. In: STREY, Marlene; RUWER, Mariana; JAEGER, Fernanda. (Org.). Violência, Gênero e Políticas Públicas. Porto Alegre: EDIPUCRS, 2004, v. 3, p. 177-194.

GUERRA, A. J. T.; SILVA, A. S.; BOTELHO, R. G. M. (Orgs.) Impactos ambientais urbanos no Brasil. Rio de Janeiro: Bertrand Brasil, 2011. 418p. 


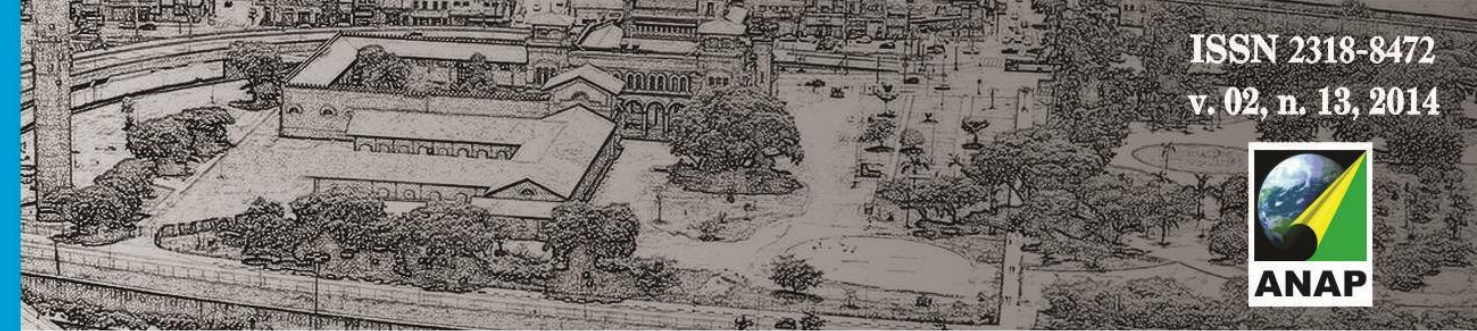

\section{Revista Nacional de}

Gerenciamento de Cidades

MARICATO, E. Metrópole na Periferia do Capitalismo: ilegalidade, desigualdade e violência. São Paulo: Editora Hucitec, 2006.

MARICATO, E. As idéias fora do lugar e o lugar fora das idéias: Planejamento urbano no Brasil. In: A cidade do pensamento único: desmanchando consensos. Otília Arantes (org). 2ª . Edição. Petrópolis. Vozes, 2006.

MINISTÉRIO DAS CIDADES. Programa Terra Urbanizada Para Todos Disponível em: <http://www.cidades.gov.br/secretarias-nacionais/programas-urbanos> . Acesso em: 12/11/2013.

MINISTÉRIO DAS CIDADES. Programa Drenagem Sustentável. Disponível em: < http://www.cidades.gov.br/secretarias-nacionais/saneamento-ambiental/programas-e-acoes1/drenagem-urbana/apoio-a-estados-e-municipios-para-elaboracao-de-projetos-de-drenagem-urbanasus> Acesso em: 12/11/2013.

OLIVEIRA, E. L. de A. Áreas de Risco nas Cidades Brasileiras: Gerenciamento e Políticas Públicas Publicado em 2012 - disponível em: http://www.partes.com.br/2012/10/29/areas-de-risco-nascidades-brasileiras-gerenciamento-e-politicas-publicas/

ROLNIK, Raquel. Estatuto da Cidade - Instrumento para as cidades que sonham crescer com justiça e beleza. In: SAULE JÚNIOR, Nelson; ROLNIK, R.. Estatuto da Cidade: novos horizontes para areforma urbana. São Paulo,Pólis, 2001. p. Disponível em: <http://www.direito.caop.mp.pr.gov.br/arquivos/File/EstatutodaCidade.pdf >. Acesso em: 18112013.

SOUZA, Celina. Políticas Públicas: Uma Revisão de Literatura. Sociologias, Porto Alegre, ano 8, no 16, jul/dez 2006, p. 20-45. 2 Disponível em: <http://www.scielo.br/scielo.php?pid=\$151745222006000200003\&script=sci_arttext\&tlng=pt>. Acesso em: 18112013.

VITTE, C. A.; GUERRA, A. J. T. Reflexões Sobre a Geografia Física no Brasil. Rio de Janeiro: Bertrand Brasil, 2004. 280p 